\title{
Practice and Function of BDSM among Sexual Vampires: A Qualitative Exploration
}

\author{
Suzanne Carré, \\ Hobart, Australia \\ suzanne.carre6@gmail.com \\ DJ Williams \\ Center for Positive Sexuality and Idaho State University (USA) \\ Hesperus \\ Current and Longitudinal Analyses of the Vampire-Identifying Subculture (USA) \\ Emily E. Prior \\ Center for Positive Sexuality
}

\section{Introduction}

In recent years, a handful of researchers have turned their attention to understanding the practices and interpretations of people who secretly identify as "real vampires" (i.e., Benecke \& Fischer, 2015; Browning, 2014, 2015c; Carré et al., 2016; Laycock, 2009a, 2009b, 2010; Williams, 2008, 2009, 2013). According to research, real vampires are rather ordinary people (Browning, 2015a, 2015b) who claim to require extra human energy in order to sustain their physical, psychological, and spiritual health (Laycock, 2009a, 2010). For such individuals, the term "vampire” refers to the process of taking energy (called "feeding”), which may occur through various means including ingesting small amounts of human or animal blood. Real vampires, in contrast to lifestyle vampires (Aaron, 2017), then, may or may not be interested in vampire myths or pop culture narratives (Browning, 2015a, 2015b).

Some real vampires report feeding on energy via sexual behavior. Sexual vampires, sometimes called Eros or tantric vampires, may include any vampire who "actively requires some sort of sexual stimuli, either produced or evoked, in order to make the act of feeding of value” (Carré et al., 2016, p. 37). In a narrative study, Williams (2015) described an intense feeding session of a vampire who apparently enjoyed taking energy through sex and blood. Using survey and interview data, Carré and colleagues (2016) found that most sexual vampires in their sample were in committed relationships; practiced diverse forms of feeding methods; and were likely to engage in bondage and discipline, dominance and submission, and sadomasochistic (BDSM) practices. Surprisingly, the majority of vampires in the Carré et al. (2016) study who practiced BDSM identified as switches, rather than dominants. All participants in the study who practiced BDSM reported feeding during BDSM scenes.

Although the authors of the present study have extensive experience in the vampire community, very little is known about sexual vampires, generally, and the specific purpose(s) of BDSM for sexual vampires, specifically. Therefore, this exploratory study investigates the BDSM activities and functions of sexual vampires who engage in such practices. 


\section{Methods}

Participants were recruited via online sites (with permission from administrators) frequented by real vampires. Fourteen sexual vampires, all from the USA, who also practice BDSM agreed to participate and completed an open-ended survey that inquired about their BDSM activities and purposes. Participants ranged in age from 21 to 47 years, identified as vampires for several years (most from 15+ years), and they also had practiced BDSM for a similar length of time. In this study, a wide range of genders were reported, with seven females, three males, one genderfluid, one non-binary, one transgender, and one transmasculine genderqueer. Sexual orientations of participants included six pansexual/omnisexual, five bisexual/bicurious, and three heterosexual. Most participants had obtained higher education and had been awarded undergraduate degrees. The survey included 12 questions focused on why vampires engage in BDSM; what activities are preferred and why; how feeding through BDSM begins; impact of sensation on feeding; and feelings and effects associated with BDSM feeding. Data analysis was conducted by applying line-by-line open coding to text, and codes were then organized to determine broad emergent themes (Charmaz, 2000).

\section{Results}

Power and Energy, Openness, Complementary Identities

Sexual vampires reported being attracted to BDSM play primarily due to power exchange and natural energy, and openness and willingness of BDSM practitioners to explore alternative activities. As one participant explained,

I feed in various ways, but sexual energy has been one of my means. I found by accident the energy exchange that can happen during 'play' and have used it as a means since....People can be more open-minded and willing to share their energy. I can directly affect and interact with the energy thus molding it to what I need at the time...

Sexual vampires generally seem to understand their BDSM and vampire identities as being separate, yet often complementary, to each other. In all but one case, individuals selfidentified as vampires for the same number or more years as they practiced BDSM, thus implying that they likely discovered kink because of their feeding needs. According to one vampire, "I had come out to myself both as a vampire and as kink at about the same time: linking the two seemed both reasonable and natural."

Some participants said the BDSM activities are not necessarily different (for purposes of feeding or otherwise), but the purpose is. For example, one participant stated, "The BDSM techniques remain the same for me. The intent, however, is different...” Another reported, "I engage in many aspects of BDSM, not all directly to do with feeding, although I think BDSM inherently lends itself to the 'dance of energy' between partners....as far as conscious, vampiric feeding, I don’t always incorporate it into play.” However, a few vampires noted that for them, some specific BDSM activities were preferred for pleasure but not feeding. 


\section{Communication and Negotiation}

Most participants explicitly mentioned the importance of communication and negotiation when engaging in BDSM activities with a partner, including when the purpose of BDSM activities is to feed. One vampire explained:

That comes in very early in discussion of interests and 'play'. I always like to make sure I have a good idea of what a play partner is looking for, wanting to get out of play, their limits and interests. That often is clearly discussed even before the subject of feeding is. Once I know their info and they know mine, we can proceed with discussion of energetic feeding...

Some participants emphasized the importance of mutual activity interest and satisfaction, reflecting care toward their donors. One stated, "[BDSM play] is based on which activities we mutually enjoy.” Another vampire reported, “I am very careful to keep everything safe and sanitary, and to make sure my donor is comfortable...”

The theme of consent and negotiation was salient when discussing beginning a feeding session. One participant noted, "I first make sure that the exchange is allowed and agreed upon.” Other vampires described beginning feeding as simply normal or natural. One explained, "My body knows what to do and does it." For a few, affection and erotic arousal in the interaction were important to begin feeding.

\section{BDSM Intensity and Edgeplay}

Participants mentioned a wide variety of preferred BDSM activities regarding generating high levels of sexual energy for feeding, including spanking, flogging, electrical play, bondage, breath play, chakra play, orgasm denial, strap-on play, vibrators, sensory deprivation, and (not surprisingly) play that involves drawing blood. For the most part, activities reported for the purpose of generating energy might be considered to be moderate to intense, though the specific activities themselves varied considerably. But there are risks when feeding on energy generated by intense play. As one vampire explained, "I am seldom comfortable with the level that intense play puts a person into as a safe space to pull energy from. I personally feel for me, subspace can be a dangerous energetic level to be at, and tampering too heavily with a person's energy could be dangerous to the sub.”

A few respondents mentioned qualitative factors, some of which varied significantly, such as ensuring the donor is relaxed, increasing donor nervousness, or increasing donor erotic arousal. Vampires varied in their responses regarding how sensations experienced in BDSM play affect feeding on sexual energy. Some reported sensation amplifies energy, for others there may be no significant impact, and a few thought that intense sensation inhibited energy. 
Physical, Psychological, and Spiritual Benefits

Findings suggest that feeding via BDSM practices is subjectively associated with various physical, psychological, and spiritual benefits. Nearly all participants reported they are very satisfied with the sexual energy obtained through feeding during BDSM play. Vampires described feeling "full," "happy," "content," "energized,” "pleasantly sated,” "almost inebriated," "relaxed,” “euphoric and alive,” "more focused,” "aware,” and "balanced."

One participant reported that feeding on sexual energy during BDSM provided many benefits: "I find I can breathe better... am in a better mood, am less anxious, and stress levels are lower," also noting that "my hormonal cycle goes more smoothly." Similarly, another participant stated that sexual feeding during BDSM practices often prevents her from experiencing multiple physical and psychological symptoms, specifically mentioning migraine headaches and depression. One vampire observed, "It's a very efficient form of feeding, and it makes deep feeding easier because there's so much emotional and spiritual intimacy." Still another noted, "[feeding] in the context of BDSM lends itself to a more sexually charged, intimate connection.”

\section{Conclusion}

Despite scholarly reports suggesting that real vampirism should be understood as an alternative identity (Laycock, 2010; Williams, 2013), many clinical professionals seem to assume, incorrectly, that vampirism must reflect some sort of underlying psychopathology (see Laycock, 2009a, 2010, 2016; Williams, 2017; Williams \& Browning, 2016; Williams \& Prior, 2015). Laycock (2016) observed that such assumptions are due to taking a person's ontological status for granted, rather than recognizing that such status is socially constructed. Indeed, there remains a strong need to recognize and set aside assumptions, in an attempt to try to understand people with unique identities, including those associated with vampirism. Indeed, the purpose of this study was to better understand BDSM practices of people who identify as sexual vampires.

Real vampires claim to need extra energy (usually human), and they report feeding on energy through various ways. Some, such as those in the present study, report feeding on sexual or erotic energy, including through participation in BDSM activity. Findings here suggest that many sexual vampires participate in BDSM for both feeding and nonfeeding (including basic pleasure) purposes, and that BDSM and vampire identities are distinct, yet complementary. Consent and communication are emphasized in BDSM play for both feeding and nonfeeding purposes, and sexual vampires have individual preferences in feeding and nonfeeding BDSM play. Finally, vampires report diverse benefits that come from sexual feeding during BDSM.

Social science research on the subjectivity of vampire self-identity is, of course, challenging. Findings from this small, self-selected sample are not generalizable. However, while much more research is warranted, this study is a useful beginning in trying to 
understand potential meanings, motivations, and practices associated with people who adopt a highly stigmatized alternative identity, particularly in a sex-negative society.

\section{References}

Aaron, M. (2017). Out of the Shadows: Shining Light on the Vampire Community. Psychology Today. Retrieved from https://www.psychologytoday.com/blog/st andard-deviations/201705/out-theshadows-shining-light-the-vampirecommunity.

Benecke, M., \& Fischer, I. (2015). Vampyres among us! Volume III: A scientific study into vampyre identity groups and subcultures. Jelgava, Latvia: Jelgavas Tipograpfia.

Browning, J. E. (2014). Interviews with the vampires. In M. Summers, The vampire in Europe: A critical edition. Berkeley, CA: Apocryphile Press.

Browning, J. E. (2015a). The real vampires of New Orleans and Buffalo: A research note towards comparative ethnography. Palgrave Communications, 1. 15006.

Browning, J. E. (2015b). What they do in the shadows: my encounters with the real vampires of New Orleans. The Conversation. Retrieved from https://heconversation.com/what-they-doin-the-shadows-my-encounters-with-thereal-vampires-of-new-orleans-39208.

Browning, J. E. (2015c). Life among the Vampires. The Atlantic. Retrieved from http://www.theatlantic.com/health/archive /2015/10/life-among-thevampires/413446/.

Carré, S., Hesperus, \& Gray, D. (2016). Sexual vampires: Myths and motivations. Journal of Positive Sexuality, 2, 37-46.

Charmaz, K. (2000). Grounded theory: Objectivist and constructionist methods. In N. K. Denzin \& Y. S. Lincoln (Eds.), Handbook of qualitative research 2nd ed. (pp. 509535).Thousand Oaks, CA: Sage.

Laycock, J. (2009a). Vampires today: The truth about modern vampirism. Westport, CT: Praeger.

Laycock, J. (2009b). Modern vampires: Your neighbors and spouses. Religion Dispatches (May 28, 2009). Retrieved on October 29, 2009 from: http://www.religiondispatches.org.
Laycock, J. (2010). Real vampires as an identity group: Analyzing the causes and effects of an introspective survey by the vampire community. Nova Religio: The Journal of Alternative and Emergent Religions, 14, 4-23.

Laycock, J. (2016). Reply to "Do we always practice what we preach? Real vampires' fears of coming out of the coffin to social workers and helping professionals.” Critical Social Work, 17(2), 83-89.

Williams, D J (2008). Contemporary vampires and (blood-red) leisure: Should we be afraid of the dark? Leisure / Loisir, 32, 519-539.

Williams, D J (2009). Deviant leisure: Rethinking "the good, the bad, and the ugly." Leisure Sciences, 31, 207-213.

Williams, D J (2013). Social work, BDSM, and vampires: Toward understanding and empowering people with nontraditional identities. Canadian Social Work, 15, 1024.

Williams, D J (2015). Intersections of vampirism and sexuality: A narrative description of a vampire feeding. In T.S. Weinberg \& S. Newmahr (Eds.), Selves, symbols, and sexualities: An interactionist anthology (pp. 265-274). Los Angeles, CA: Sage.

Williams, D J (2017). Self-identified vampirism and risk for false positives: A case example of team homicide and implications for forensic behavioral science. Journal of Forensic Sciences, 62, 819-821.

Williams, D J, \& Browning, J. E. (2016). Looking inside the coffin: An overview of contemporary human vampirism and its relevance for forensics professionals. In M. Arntfield \& M. Danesi (Eds.), The criminal humanities: An introduction (pp. 117-134). New York: Peter Lang.

Williams, D J, \& Prior, E. E. (2015). Do we always practice what we preach? Real vampires' fears of coming out of the coffin to social workers and helping professionals. Critical Social Work, 16(1), 79-92. 